\title{
A review of local anesthetic cardiotoxicity and treatment with lipid emulsion
}

This article was published in the following Dove Press journal:

Local and Regional Anesthesia

25 February 2010

Number of times this article has been viewed

\author{
Emma Bourne' \\ Christine Wright ${ }^{\prime}$ \\ Colin Royse ${ }^{2}$ \\ 'Cardiovascular Therapeutics \\ Unit, Department of Pharmacology, \\ University of Melbourne; ${ }^{2}$ Anesthesia \\ and Pain Management Unit, \\ Department of Pharmacology, \\ University of Melbourne
}

\begin{abstract}
Cardiovascular collapse from accidental local anesthetic toxicity is a rare but catastrophic complication of regional anesthesia. The long-acting amide local anesthetics bupivacaine, levobupivacaine and ropivacaine have differential cardiac toxicity, but all are capable of causing death with accidental overdose. In recent times, the chance discovery that lipid emulsion may improve the chance of successful resuscitation has lead to recommendations that it should be available in every location where regional anesthesia is performed. This review will outline the mechanisms of local anesthetic toxicity and the rationale for lipid emulsion therapy.
\end{abstract}

Keywords: local anesthetic, cardiac toxicity, lipid emulsion, cardiovascular collapse

\section{Introduction}

Topical application of agents which essentially 'numb' have been used since the introduction of the Peruvian compound known as khoka to Europe in the early 1500's where it became commonly known as cocaine. After isolation of the main alkaloid in cocaine by Neimann in 1860, Ritter von Schroff described its use as a narcotic, and Percy was the first to propose its use as a topical local anesthetic in 1856. Along with increasing use in clinical settings, the toxicity of cocaine became apparent almost simultaneously with the incidence of central nervous system and cardiovascular system toxicity increasing parallel to its use. The common practice of treating cocaine toxicity with barbiturates did not help in reducing cocaine-related deaths. ${ }^{1}$

The need for a local anesthetic with reduced toxicity led to the development of numerous compounds. Amino ester local anesthetics were developed in the early 1900s producing benzocaine in 1900 and procaine in 1905. Procaine use has become confined to infiltration anesthesia as it has demonstrated low potency, slow onset, short duration and low ability to infiltrate tissue. Tetracaine was the last ester type local anesthetic developed in 1930, but is no longer used clinically.

Amide anesthetics became the next major development pathway, stemming from nirvaquine which was synthesized in 1898 . Nirvaquine experienced very limited use however due to its local irritant properties. This led to a substitution of the local amide ring to produced lidocaine in 1944 which was introduced into clinical practice in $1948 .{ }^{1}$ Since lidocaine, local anesthetic agents have been designed by integrating on to the amide motif. This gave rise to (chronologically) mepivacaine, prilocaine, bupivacaine, etidoacaine and articaine being developed in to the 1970s.

After the introduction of bupivacaine, it became apparent that accidental overdose was often fatal, and responded poorly to conventional resuscitation methods. ${ }^{2}$ This led
Correspondence: Colin Royse Department of Pharmacology, University of Melbourne, Victoria 3010, Australia

Tel +61383445673

Fax +61383445193

Email colin.royse@unimelb.edu.au 
to a search for long acting local anesthetics with improved therapeutic margins, in order to reduce the risk of death in the event of accidental (usually intravenous) overdose.

The amino amide ropivacaine, a derivative of mepivacaine, was introduced in 1996 as the safest long acting local anesthetic. Ropivacaine is produced as the $\mathrm{S}(-)$ enantiomer only, as some studies have suggested a decrease in toxicity associated with the $\mathrm{S}(-)$ enantiomer when compared to the racemate. The $\mathrm{S}(-)$ enantiomer of bupivacaine was also found to be more potent ${ }^{3}$ and less cardiotoxic than the $\mathrm{R}(+)$ enantiomer ${ }^{4}$ leading to the selection of the $\mathrm{S}(-)$ enantiomer, levobupivacaine, as a safer alternative to bupivacaine. Both drugs are marketed as safer than bupivacaine on the basis of animal studies.

Avoiding local anesthetic toxicity is primarily based on good practice, and secondly on treating toxicity once it has occurred. Most anesthesiologists will be familiar with practice guidelines for safe regional anesthesia, which include an estimate of maximal dose, establishment of intravenous access, adequate monitoring, access to resuscitation equipment, aspiration prior to injection, and thorough patient evaluation to determine factors that may influence absorption and biotransformation. The advent of ultrasound guided regional anesthesia may further improve safety by the visualization of anesthetic solution spread with injection, though this has yet to be fully tested in clinical trials.

Treatment options are traditionally based on cardiovascular support, including fluids, vasopressors, and inotropes, in addition to securing the airway and controlling central nervous system toxicity including seizures. The chance discovery, however, that lipid emulsions can help reverse catastrophic cardiovascular collapse, has led to clinical awareness and the establishment of guidelines for the use of lipid emulsions in the treatment of severe cardiovascular toxicity from local anesthesia.

The aim of this review is to identify the mechanisms of local anesthetic induced cardiotoxicity and treatment using lipid emulsion.

\section{Mechanisms of action}

Bupivacaine, levobupivacaine and ropivacaine are three long acting amide-based local anesthetics most commonly used in clinical practice. Local anesthetic agents all work by preventing the conduction of nerve impulses primarily in nerve cell membranes by inhibition of voltage-gated $\mathrm{Na}^{+}$channels. Their time to onset, duration of action, and adverse effects are all drug-specific, though share similar characteristics.
Binding can occur selectively to the inactivated, closedstate of the channel to keep the ion channel closed and unable to undergo conformational changes during an action potential, thereby preventing conduction. Ion channels also present another binding site within the pore that is only accessible during the open-activated state. Local anesthetics bind less tightly to this phase, so each $\mathrm{Na}^{+}$channel opening develops additional conduction block. For this reason the degree of block produced by a given concentration depends on how the nerve has been stimulated and its resting membrane potential. Consequently, a resting nerve is much less sensitive to local anesthetic block than a nerve that is continuously stimulated, explaining the differential sensitivity properties of different nerve fibers.

The binding site for local anesthetics, in their charged form, is only accessible from inside the cell membrane, so local anesthetic agents applied externally must cross nerve cell membranes before they exert their actions from within the cytosol. ${ }^{5}$ In addition to blocking $\mathrm{Na}^{+}$channels, ropivacaine has been found to bind to other channel proteins, such as cloned human cardiac $\mathrm{K}^{+}$channels (hKv1.5) to block potassium currents. ${ }^{6}$ A number of anesthetics, including bupivacaine and ropivacaine, have also been shown to block L-type $\mathrm{Ca}^{2+}$ channels in rat cerebrocortical membranes. ${ }^{7}$

\section{Local anesthetic pharmacokinetics and metabolism}

Being mostly secondary and tertiary amines, local anesthetic agents are amphiprotic and can exist as neutral or charged molecules, depending on the $\mathrm{pH}$ of the solution and the $\mathrm{pKa}$ of the local anesthetic. The charged particle has been revealed as the active molecular form of the local anesthetic that combines with the $\mathrm{Na}^{+}$channel to cause conduction block, and the neutral, lipophilic form is responsible for diffusion and tissue penetration. ${ }^{5}$ This means the $\mathrm{pH}$ of the solution in which the local anesthetic is suspended can have a pronounced effect on its level of conduction block. In vivo, the $\mathrm{pH}$ of the solution matters less as the dose can quickly equilibrate within the body or blood vessels, unless the tissue milieu is abnormal such as in infected tissue.

\section{Patient factors}

Most severe local anesthetic toxicity events results from inadvertent intravascular injection of local anesthetic. ${ }^{8}$ However, toxicity can occur from an imbalance in absorption versus biotransformation of the drug. Factors that increase absorption include injection into highly vascular tissue, and especially in patients with high cardiac output. This is also 
problematic in trauma and other low cardiac output situations, where absorption can suddenly increase if cardiac output is restored. Local anesthetics are generally highly protein bound, particularly to alpha-1 glycoprotein (AAG). In pregnancy, for example, AAG is reduced and cardiac output is increased, potentially increasing the plasma levels following large volume infiltration. Elderly patients have reduced cardiac output and lower muscle mass, which can lead to more prolonged absorption. In uremia the initial rate of uptake is increased as well as reduced clearance by the kidney can lead to increased plasma levels. ${ }^{9}$ Other pre-existing medical conditions such as cardiac failure, or cardiac conduction block, or rare diseases such as mitochondrial defects could increase the toxic potential of local anesthetics.

\section{Biotransformation}

Ester based local anesthetics are primarily hydrolyzed and inactivated by a plasma esterase, possibly plasma cholinesterase, and a smaller amount of hydrolysis occurs in the liver. Amide-linked local anesthetics are generally degraded by the hepatic endoplasmic reticulum in which the initial reactions involve N-dealkylation and then hydrolysis. ${ }^{10}$ This means slower removal of drug from the body and sustained elevations of the plasma drug concentrations. This is a problem if competitive metabolism occurs with compounds that also utilize cytochrome $\mathrm{P}_{450}$ pathways. Drugs such as acetaminophen could theoretically extend metabolic processing time and affect plasma drug concentrations to further increase risk of systemic toxicity.

Amide-linked local anesthetics are also extensively bound to plasma proteins, in particular alpha-1 glycoprotein. Many factors, such as cancer, surgery, pregnancy or smoking can alter protein levels in the blood. This produces an increased free fraction of drug and can increase the toxicity potential.

The effect of general anesthesia in sheep ${ }^{11}$ caused plasma local anesthetic concentrations to increase due to cardiovascular depression, leading to slower efflux from visceral to nonvisceral organs. However, less severe cardiovascular arrhythmias occurred in animals under general anesthesia.

Neuroexcitation from local anesthetic toxicity in awake subjects caused acute cardiovascular stimulation leading to more rapid redistribution and clearance, with some fatalities occurring only in awake subjects. ${ }^{11}$ This raises questions concerning the ability of general anesthesia to protect against arrhythmias or death from local anesthetic toxicity.

\section{Clinical presentation}

Local anesthetic toxicity presents initially with central nervous system (CNS) signs involving light-headedness, dizziness and tinnitus, leading to unresponsiveness and drowsiness. Progression of toxicity can lead to tonic-clonic seizures, loss of consciousness and coma. Cardiovascular signs are associated with more severe toxicity. Early cardio-excitatory effects such as tachycardia and increasing blood pressure are followed quickly by hypotension that is unresponsive to resuscitation leading to cardiovascular collapse and death.

Combined regional and general anesthesia poses an additional problem because of the added cardiovascular depression from the anesthetic, but perhaps even more importantly, that the early warning signs of toxicity will be obscured. General anesthetics have been shown to decrease contractility and cause hypotension ${ }^{12}$ which are exacerbated by the cardiovascular depressor effects of local anesthetic agents. ${ }^{13}$ Severe hypotension unresponsive to fluid administration or vasopressor support may be the initial presentation of local anesthetic toxicity, which may be too late to avoid cardiac arrest.

\section{Local anesthetic mechanisms of action and toxicity}

Local anesthetic toxicity has mostly been attributed to high plasma concentrations. Primarily, $\mathrm{Na}^{+}$channel binding specificity is lost or negated and other cation channels are involved. The pattern of affected tissues during local anesthetic induced toxicity includes those with the highest aerobic demand and least tolerance for hypoxia, such as the heart, lungs and central nervous system (CNS). While there is still a fairly large gap in the literature as to the pathways by which toxicity is induced by local anesthetic agents, many studies are emerging that are looking further than the more simple theories of mechanistic actions.

In vivo studies have revealed bupivacaine to be a negative inotropic agent, with intravenous infusions of these drugs causing significant decreases in blood pressure and heart rate through alterations in electrical excitability of the heart, dilatation of blood vessels and inhibition of the firing rate of the sinoatrial node. Typical effects on the electrocardiogram (ECG) include widening of the QRS complex and lengthening of the PR interval. ${ }^{14}$ Lefrant and colleagues ${ }^{15}$ further demonstrated that bupivacaine, more potently than ropivacaine, increases left ventricular end diastolic pressure, and alters ventricular conduction via the His-bundle. Royse and colleagues ${ }^{16}$ demonstrated less depression of contractility with 
ropivacaine compared to levobupivacaine or bupivacaine, whereas bupivacaine had a pronounced vasoconstrictor effect in comparison to ropivacaine or levobupivacaine. The combination of depressed contractility and increased afterload will have an additive deleterious effect on cardiac output.

Rapid infusion of bupivacaine $0.5-2 \mathrm{mg} / \mathrm{kg}$ has been shown to inhibit baroreflex sensitivity in conscious rats, involving primarily vagal components of the baroreflexheart rate pathways. ${ }^{17}$ Five-minute infusions of bupivacaine ( $3 \mathrm{mg} / \mathrm{kg}$ ) and ropivacaine $(6 \mathrm{mg} / \mathrm{kg}$ ) have also been shown to significantly suppress baroreflex-sensitivity, with alkalotic and acidotic states altering the level of baroreflex sensitivity suppression in rats. ${ }^{18}$ Pickering and colleagues ${ }^{19}$ further investigated the effect of bupivacaine on baroreflex sensitivity in rat working heart-brainstem preparations, where bupivacaine was applied via aortic perfusions at concentrations between 1 and $6 \mu \mathrm{g} / \mathrm{mL}$. This study demonstrated that bupivacaine is selectively toxic to the cardiovascular control centre in the brainstem, targeting specific cardiovascular control processes without affecting the chemoreflex or phrenic nerve control of respiration. Another important finding of this study was that the pressor effect of systemic bupivacaine was inhibited by prazosin, suggesting bupivacaine is acting at the $\alpha_{1}$-adrenoceptor or by an indirect action to release noradrenaline from sympathetic terminals or to block catecholamine re-uptake.

Baroreflex inhibition by bupivacaine in rats was shown to occur at a plasma concentration of $1.8 \mathrm{mg} / \mathrm{L} .{ }^{17} \mathrm{In}$ humans, initial CNS signs of toxicity, including tinnitus, tingling and light-headedness, occurred at venous concentrations of 2.62 and $2.25 \mu \mathrm{g} / \mathrm{mL}$ of bupivacaine and levobupivacaine respectively after intravenous infusion. Both concentrations produced small increases in PR and QT intervals of the ECG. ${ }^{20}$ Knudsen and colleagues ${ }^{21}$ showed that the maximum tolerated unbound plasma arterial concentrations of ropivacaine $(0.6 \mathrm{mg} / \mathrm{L})$ were twice as high as bupivacaine $(0.3 \mathrm{mg} / \mathrm{L})$ after intravenous infusion of the drugs into human volunteers. The onset of CNS signs therefore appears to be much lower than the concentrations needed to elicit cardiovascular depression and inhibit baroreflex pathways (negating species differences).

Blocked $\mathrm{Ca}^{2+}$-channels in myocardial tissue is thought to be one of the main mechanisms of local anesthetic-induced cardiac depression. Bupivacaine and ropivacaine have been shown to decrease peak systolic intracellular $\mathrm{Ca}^{2+}$ in a concentration-dependent manner to decrease the twitch tension in papillary muscles of ferrets in vitro. ${ }^{22}$ It has also been shown that bupivacaine has an effect on rat isolated myocyte sensitivity to calcium, along with reducing the amount of $\mathrm{Ca}^{2+}$-activated tension in trabeculae. ${ }^{23}$ This study also demonstrated that there is a $\mathrm{Ca}^{2+}$-independent pathway for bupivacaine mediated cardiac muscle relaxation, as it reversed the induced tension by lowering the $\mathrm{Mg}$-adenosine triphosphate (MgATP) concentration in ventricular trabeculae of ferrets. MgATP essentially acts as a primer in the contraction-coupling cycle for muscular contraction. MgATP binds to myosin where it is hydrolyzed and allows binding of actin to initiate the sliding sequence of thick and thin filaments, resulting in muscle contraction. ${ }^{24}$ Thus MgATP fuels the actin-myosin cross bridge cycle and $\mathrm{Ca}^{2+}$ is responsible for its regulation. This interference with ATP concentration by bupivacaine adds another layer to the complexity of local anesthetic mechanisms of action and toxicity.

Mechanisms outside of calcium channel blocking have been found to contribute to the myocardial depression caused by local anesthetic agents, specifically, effects on oxygen consumption and metabolism in cardiac myocytes. Bupivacaine and ropivacaine have both been shown to act as uncouplers between oxygen consumption and phosphorylation of adenosine diphosphate at the level of complex I (NADH ubiquinones reductase) in rat heart isolated mitochondria and saponin-skinned left ventricle fibers in vitro. ${ }^{25}$

Bupivacaine has also been shown to inhibit carnitineacylcarnitine transferase (CACT) in rat cardiac interfibrillar mitochondria. CACT is the only enzyme responsible for transporting acylcarnitines across mitochondrial membranes in the fatty acid transport chain during phase I mitochondrial respiration important for aerobic metabolism. ${ }^{26}$ This may be a key factor in the nature of local anesthetic-induced toxicity being unresponsive to advanced cardiac resuscitation techniques.

Mechanisms of local anesthetic agents outside of the heart and myocardium are also of interest as hypotension caused by local anesthetic toxicity is thought to be due to overall vasodilatation as well as decreased myocardial function. Lida and colleagues ${ }^{27}$ investigated the effects of bupivacaine and ropivacaine in spinal pial vessel diameter and found that concentrations of $10^{-8}$ to $10^{-3} \mathrm{M}$ applied locally to the spinal window caused no changes in systemic hemodynamics, but ropivacaine induced constriction and bupivacaine dilatation of the vessels.

Effects of bupivacaine in human umbilical vessels have been investigated to highlight any direct effects of the local anesthetic agent on vasculature without nervous input. Two studies conducted on human umbilical artery preparations 
by Bariskaner et $\mathrm{al}^{28}$ and Rossner et $\mathrm{al}^{29}$ showed respectively that adrenoceptors, nitric oxide synthase and prostaglandins do not appear to be responsible pathways for vascular contractions induced by ropivacaine or bupivacaine on preconstricted vessels, and that bupivacaine is responsible for increasing intracellular $\mathrm{Ca}^{2+}$ in patterns consistent with phasic tension, as well as altering the resting membrane potential. Monuszko and colleagues ${ }^{30}$ showed that bupivacaine $8.6 \mu \mathrm{M}$ to $430 \mu \mathrm{M}$ caused contraction of resting umbilical arteries and caused relaxation in $50 \%$ of the vessels when bupivacaine was added to potassium chloride pre-contracted vessels. Tokinaga and colleagues ${ }^{31}$ found that the ropivacaine-induced contraction at concentrations of $3 \times 10^{-5}$ to $3 \times 10^{-3} \mathrm{M}$ was only inhibited in the presence of L-type $\mathrm{Ca}^{2+}$-channel and IP3-receptor antagonists, however the intracellular calcium was completely abolished, suggesting calcium-independent mechanisms were responsible for local anesthetic induced vasoactivity. Hahnenkamp and colleagues ${ }^{32}$ also showed low concentrations $\left(10^{-10}-10^{-6} \mathrm{M}\right)$ of bupivacaine to be an endothelium-independent inhibitor of thromboxane- $\mathrm{A}_{2}$ induced vasoconstriction in rat thoracic aorta.

The effects of local anesthetic agents on vascular tone have also been investigated using laser Doppler imaging in human volunteers. Bupivacaine and levobupivacaine concentrations higher than $0.625 \%$ induced vasodilatory responses when measuring microvascular skin blood flow. ${ }^{33}$ As well, co-administration with adrenaline diminished this vasodilatation diminished to lower than saline responses, indicating net vasoconstriction. This could have implications in the metabolism of the local anesthetic agents and their duration of action. Vasodilator effects of local anesthetics have been tied to the nitric oxide synthase (NOS) pathway, with lidocaine vasodilatation being reduced when co-administered with NG-nitro-L-arginine methyl ester (L-NAME), a NOS inhibitor. ${ }^{34}$ These findings are not in accord with those of Bariskaner and colleagues, and perhaps elucidate the difference in response to blood vessels with and without nervous influence to highlight different pathways of local anesthetic vasoactivity.

\section{Lipid emulsion}

Successful treatment for local anesthetic-induced cardiovascular collapse has been uncommon unless there is ready access to cardiopulmonary bypass. Recently the use of lipid emulsions to treat local anesthetic overdose has moved from the research lab to clinical practice. Not only is the mechanism of action still unclear, but the potential to develop and refine the therapy/treatment is of great excitement due to initial successes with its use in animal studies and subsequent case reports of success in humans.

It is known that circulating free fatty acids exacerbate cellular damage during myocardial ischemia, or reduced flow states, through the accumulation of toxic metabolic intermediates. It followed on that the interruption of oxygen-energy coupling caused by bupivacaine would also exacerbate myocardial damage. The initiation of lipid emulsions as a therapy for local anesthetic toxicity was discovered by a chance observation during a series of experiments set out to test whether a lipid emulsion infusion would increase bupivacaine-induced arrhythmias. ${ }^{35}$ It was hypothesized that lipid emulsions would add to the toxicity of bupivacaine on the basis that the local anesthetic agent inhibits CACT, generating a surplus of upstream intracellular metabolic moieties stemming from fatty acid presence in the blood that exert damaging effects on cardiac cells. The theory suggested that extent of bupivacaine toxicity would be dependent upon initial concentrations of free fatty acids in the plasma, implying that high free fatty acid concentrations from lipid emulsions would aggravate bupivacaine-induced arrhythmias and cardiac depression.

Since this discovery that lipid emulsions are a protection against local anesthetic toxicity, animal studies have been published in various species demonstrating beneficial effects and attempting to indentify mechanisms of protection. A brief summary of some key animal studies that utilize lipid emulsion for reversal of local anesthetic and lipophilic drug toxicity is given listed in Table 1 .

These studies have led to the emergence of human case reports where not just local anesthetic toxicity, ${ }^{36-39}$ but also other lipophilic drug-induced cardiovascular collapse ${ }^{38,40}$ that had been unresponsive to all avenues of resuscitation, was rapidly reversed with a lipid emulsion bolus and/or infusion. Weinberg has been a chief campaigner for lipid emulsions to be readily available in all hospitals where local anesthetic nerve blocks are used. ${ }^{41-43}$ This has led to lipid emulsion being a first line therapy in some clinical cases, where it was almost instantly successful in reversing the cardiovascular and CNS effects of local anesthetic toxicity. ${ }^{39,44}$

There are a number of lipid emulsions available, being composed mainly of soy bean and egg phospholipids with triglyceride chain length altering between products. For example, Intralipid is a $100 \%$ long-chain triglyceride emulsion, Medialipide ${ }^{\circledR}$ is a 50:50 medium-chain:long-chain triglyceride emulsion and Structolipid ${ }^{\circledR}$ is a 64:36 long-chain: medium-chain triglyceride emulsion. 
Table I In vivo studies of lipid emulsion infusion for the treatment of cardiovascular collapse

\begin{tabular}{|c|c|c|c|c|}
\hline Study & Species & Drug & Lipid infusion & Results \\
\hline *Weinberg ${ }^{35}$ & Rats & Bupivacaine & $\begin{array}{l}\text { Intralipid } 10 \%, 20 \% \\
\text { and } 30 \%\end{array}$ & $\begin{array}{l}\text { Doses needed to induce asystole increased with the increase } \\
\text { in \% Intralipid. Intralipid shifted the bupivacaine dose-response } \\
\text { curve to the right. }\end{array}$ \\
\hline *Weinberg ${ }^{51}$ & Dogs & Bupivacaine & $20 \%$ Intralipid & $\begin{array}{l}\text { All controls unable to be resuscitated, all lipid infused dogs } \\
\text { were resuscitated. }\end{array}$ \\
\hline *Harvey ${ }^{52}$ & Rabbits & Clomipramine & $20 \%$ Intralipid & $\begin{array}{l}\text { Intralipid-treated animals regained hemodynamic stability, } \\
\text { including cardiac activity, faster and to a greater extent than } \\
\text { other treatment groups. } \\
\text { Part 2: Intralipid group regained cardiac activity, all sodium } \\
\text { bicarbonate treated rabbits did not. }\end{array}$ \\
\hline *Harvey ${ }^{53}$ & Rabbits & Propranolol & $20 \%$ Intralipid & Mean arterial pressure was greater in Intralipid treated group. \\
\hline Weinberg ${ }^{54}$ & $\begin{array}{l}\text { Rat Langendorff- } \\
\text { isolated heart }\end{array}$ & Bupivacaine & I\% Intralipid $10 \mathrm{~g} / \mathrm{L}$ & $\begin{array}{l}\text { Lipid infusion resulted in more rapid return of heart rate and } \\
\text { recovery of rate pressure product. Lipid treatment resulted in } \\
\text { more rapid loss of bupivacaine from heart tissue. }\end{array}$ \\
\hline
\end{tabular}

*Anesthetized preparations.

A suggested mechanism of action of reversal of local anesthetic toxicity by lipid emulsions is the "lipid sink" theory, where the lipophilic drugs selectively bind into the lipid emulsion over body tissues, enabling the lipid emulsion to act like a sink that drain the local anesthetic from the plasma. This theory is supported by a study in which the "shake-flask" method was used literally in vitro to measure the extent of emulsification of bupivacaine, levobupivacaine and ropivacaine. ${ }^{45}$ The extent of local anesthetic binding to Intra$\operatorname{lipid}^{\circledR}(20 \%)$ was shown to be roughly 2.5 times more than Medialipide (20\%), and bupivacaine and levobupivacaine were more extensively bound than ropivacaine. The lipid partition coefficients for bupivacaine and levobupivacaine are the same ${ }^{28}$ versus the less soluble ropivacaine. ${ }^{9}$ This raises questions as to the clinical relevance of the difference in binding affinities to different local anesthetics and whether or not this may affect the dose and type of lipid emulsion and extent to which the over-dose is reversed.

The attraction of the lipid sink theory is due to its theoretical simplicity. It states that the lipid is the favored compartment over other body areas for local anesthetic binding. However, if the lipid is binding the local anesthetics in the blood, would this not then predict that serum local anesthetic concentrations would increase after Intralipid administration as they become bound to plasma lipids? Some initial findings so far have shown decreased local anesthetic concentrations in the plasma. Litz and colleagues ${ }^{39}$ found levels of mepivacaine decreased faster after Intralipid infusion than predicted by mepivacaine's published pharmacokinetics data. An editorial by Weinberg ${ }^{42}$ suggested that in light of this, Intralipid perhaps worked by increasing metabolism and distribution or by changing local anesthetic partition away from receptors into lipid within tissues rather than by binding the drug itself.

The biological properties and metabolic fate of lipid emulsions are similar to endogenous chylomicrons. Circulating lipoprotein lipase hydrolyzes triglycerides, releasing free fatty acids which can then be taken up by tissues and utilized in the oxidative metabolism process. ${ }^{46}$ Findings that bupivacaine inhibits CACT, which is a porterantiporter in the inner mitochondrial membrane required for fatty acid transfer into the mitochondrial matrix for oxidative metabolism, ${ }^{26}$ lead to the hypothesis that lipid rescue may as well work through its release of free fatty acids. Fatty acids serve during normal aerobic metabolism as the chief substrate to meet the high metabolic demands during times of cardiovascular stress. Thus, addition of large amount of free fatty acids would work via mass action to increase the flux of acylcarnitines into the mitochondrial matrix of cardiomyocytes and re-enable oxygen-energy coupling in cardiac tissue.

A study conducted to further investigate the influence of fatty acid metabolism on the development and progress of bupivacaine-induced cardiotoxicity was conducted by Edelman and colleagues. ${ }^{47}$ Rat-isolated cardiac mitochondria were retrograde perfused with either a free fatty acid substrate for metabolism or carbohydrates. Hearts utilizing the carbohydrate substrate metabolism were found to be significantly less susceptible to bupivacaine toxicity than those utilizing fatty acid metabolism. This further supports the basis for lipid emulsion lending more than a lipid phase that is able to extract local anesthetics from the plasma. 


\section{Risks to treatment}

Even the empiric use of lipid emulsion therapy appears to lack any acute risks. Lipid emulsions have been clinically used and well tolerated by patients receiving parenteral nutrition for a prolonged duration who require supplementation of essential fatty acids and calories. Although lipid infusions have been associated with a variety of complications, such as cytokine production by mononuclear white cells to increase infection risks, thrombolytic production during intravenous administration, allergic reactions including anaphylaxis, and even pulmonary emboli if the fat particles are too large, ${ }^{48}$ these risks are mainly seen with chronic use, with allergy/ anaphylaxis being the most likely to occur with the short term use of lipid emulsion rescue therapy for local anesthetic toxicity. There are, however, emerging reports on the interaction of lipid therapy with conventional resuscitation techniques. Hiller and colleagues ${ }^{49}$ investigated the addition of epinephrine to lipid therapy in a local anesthetic induced cardiac arrest preparation in rabbits. They found that epinephrine improved initial circulation, but lipid infusion produced a slower but more sustained recovery. Epinephrine doses exceeding $10 \mu \mathrm{g} / \mathrm{kg}$ resulted in worse outcome, possibly related to lactic acidosis. However, Mahr and colleagues, ${ }^{50}$ reported worse outcome with lipid and epinephrine versus vasopressin and epinephrine in a porcine preparation of bupivacaine induced cardiac arrest, with two minutes of untreated hypoxia prior to resuscitation. All five pigs survived in the vasopressin/epinephrine group whereas none of the lipid group survived. Whilst these are animal preparations, they do suggest that we should exercise caution in considering lipid therapy to be a panacea for successful treatment of local anesthetic induced toxicity.

\section{Clinical use}

Based on the available evidence, there seems no logical reason to withhold lipid emulsions as a treatment for local anesthetic and lipophilic drug overdoses, though caution should be exercised with co-administration of high-dose epinephrine. While mechanisms of action and toxicity are still being discovered, the introduction of clinical 'rescue' kits containing Intralipid and preliminary dosing procedures is highly recommended, most strongly by Weinberg. ${ }^{42}$ For information on implementing lipid emulsion therapy visit the website www.lipidrescure.org. The Association of Anesthetists of Great Britain and Ireland has also released guidelines for the use of lipid rescue therapy (see http//www.aagbi. org/publications/guidelines). These guidelines also recommend adjuvant therapies and practical guidelines for the management of these patients. In brief, the recommendation is to administer an intravenous bolus injection of Intralipid $20 \% 1.5 \mathrm{~mL} / \mathrm{kg}$ over one minute followed by an intravenous infusion of $0.25 \mathrm{~mL} / \mathrm{kg} / \mathrm{min}$. The bolus should be repeated twice at 5 minute intervals with an increased infusion rate to $0.5 \mathrm{~mL} / \mathrm{kg} /$ minutes if an adequate circulation has not been restored. It is recommended that the infusion rate is continued until an adequate stable circulation has been restored. The guidelines stress that other resuscitating measures such as cardiopulmonary resuscitation, seizure control, and airway management are important aspects of management, and that cardiopulmonary bypass if available should be considered. There seems to be no logical reason to withhold lipid therapy simply because of "lack of evidence" - clinical reports and animal studies are already showing promise of this novel therapy. Whilst the most important measure to reduce toxicity is good anesthetic practice, it is logical that lipid emulsions should be available in the resuscitation carts in operating rooms and other locations where regional anesthesia is performed, so that immediate access use is possible in the event of catastrophic toxicity.

\section{Disclosures}

The authors report no conflicts of interest relevant to this research.

\section{References}

1. Ruetsch YA, Boni T, Borgeat A. From cocaine to ropivacaine: the history of local anesthetic drugs. Curr Top Med Chem. 2001;1(3): 175-182.

2. Albright G. Cardiac arrest following regional anesthesia with etidocaine or bupivacaine. Anesthesiology. 1979;51:285-287.

3. Trachez MM, Zapata-Sudo G, Moreira OR, Chedid NG, Russo VF, Russo EM, et al. Motor nerve blockade potency and toxicity of non-racemic bupivacaine in rats. Acta Anaesthesiol Scand. 2005;49(1):66-71.

4. Zapata-Sudo G, Trachez MM, Sudo RT, Nelson TE. Is comparative cardiotoxicity of $\mathrm{S}(-)$ and $\mathrm{R}(+)$ bupivacaine related to enantiomerselective inhibition of L-type $\mathrm{Ca}(2+)$ channels? Anesth Analg. 2001;92(2): 496-501.

5. Ritchie JM, Ritchie B, Greengard P. The active structure of local anesthetics. J Pharmacol Exp Ther. 1965;150(1):152-159.

6. Valenzuela C, Delpon E, Franqueza L, Gay P, Snyders DJ, Tamargo J. Effects of ropivacaine on a potassium channel (hKv1.5) cloned from human ventricle. Anesthesiology. 1997;86(3):718-728.

7. Hirota K, Browne T, Appadu BL, Lambert DG. Do local anaesthetics interact with dihydropyridine binding sites on neuronal L-type $\mathrm{Ca}^{2+}$ channels? Br J Anaesth. 1997;78(2):185-188.

8. Felice K, Schumann H. Intravenous lipid emulsion for local anesthetic toxicity: a review of the literature. J Med Toxicol. 2008;4(3):184-191.

9. Rosenberg PH, Veering BT, Urmey WF. Maximum recommended doses of local anesthetics: a multifactorial concept. Reg Anesth Pain Med. 2004;29(6):564-575.

10. Oda Y, Furuichi K, Tanaka K, Hiroi T, Imaoka S, Asada A, et al. Metabolism of a new local anesthetic, ropivacaine, by human hepatic cytochrome P450. Anesthesiology. 1995;82(1):214-220. 
11. Copeland SE, Ladd LA, Gu XQ, Mather LE. The effects of general anesthesia on whole body and regional pharmacokinetics of local anesthetics at toxic doses. Anesth Analg. 2008;106(5):1440-1449.

12. Royse CF, Liew DF, Wright CE, Royse AG, Angus JA. Persistent depression of contractility and vasodilation with propofol but not with sevoflurane or desflurane in rabbits. Anesthesiology. 2008;108(1): 87-93.

13. Copeland SE, Ladd LA, Gu XQ, Mather LE. The effects of general anesthesia on the central nervous and cardiovascular system toxicity of local anesthetics. Anesth Analg. 2008;106(5):1429-1439.

14. de La Coussaye JE, Eledjam JJ, Bruelle P, Lefrant JY, Bassoul B, Peray PA, et al. Mechanisms of the putative cardioprotective effect of hexamethonium in anesthetized dogs given a large dose of bupivacaine. Anesthesiology. 1994;80(3):595-605.

15. Lefrant JY, de La Coussaye JE, Ripart J, Muller L, Lalourcey L, Peray PA, et al. The comparative electrophysiologic and hemodynamic effects of a large dose of ropivacaine and bupivacaine in anesthetized and ventilated piglets. Anesth Analg. 2001;93(6):1598-1605.

16. Royse CF, Royse AG. The myocardial and vascular effects of bupivacaine, levobupivacaine, and ropivacaine using pressure volume loops. Anesth Analg. 2005;101(3):679-687.

17. Chang KS, Morrow DR, Kuzume K, Andresen MC. Bupivacaine inhibits baroreflex control of heart rate in conscious rats. Anesthesiology. 2000; 92(1):197-207.

18. Watanabe $\mathrm{Y}$, Dohi S, Iida H, Ishiyama $\mathrm{T}$. The effects of bupivacaine and ropivacaine on baroreflex sensitivity with or without respiratory acidosis and alkalosis in rats. Anesth Analg. 1997;84(2): 398-404.

19. Pickering AE, Waki H, Headley PM, Paton JF. Investigation of systemic bupivacaine toxicity using the in situ perfused working heart-brainstem preparation of the rat. Anesthesiology. 2002;97(6):1550-1556.

20. Bardsley H, Gristwood R, Baker H, Watson N, Nimmo W. A comparison of the cardiovascular effects of levobupivacaine and rac-bupivacaine following intravenous administration to healthy volunteers. Br J Clin Pharmacol. 1998;46(3):245-249.

21. Knudsen K, Beckman Suurkula M, Blomberg S, Sjovall J, Edvardsson N. Central nervous and cardiovascular effects of i.v. infusions of ropivacaine, bupivacaine and placebo in volunteers. Br J Anaesth. 1997;78(5): 507-514.

22. Mio Y, Fukuda N, Kusakari Y, Amaki Y, Tanifuji Y, Kurihara S. Comparative effects of bupivacaine and ropivacaine on intracellular calcium transients and tension in ferret ventricular muscle. Anesthesiology. 2004;101(4):888-894.

23. Mio Y, Fukuda N, Kusakari Y, Tanifuji Y, Kurihara S. Bupivacaine attenuates contractility by decreasing sensitivity of myofilaments to $\mathrm{Ca}^{2+}$ in rat ventricular muscle. Anesthesiology. 2002;97(5):1168-1177.

24. Maughan DW. Kinetics and energetics of the crossbridge cycle. Heart Fail Rev. 2005;10(3):175-185.

25. Sztark F, Malgat M, Dabadie P, Mazat JP. Comparison of the effects of bupivacaine and ropivacaine on heart cell mitochondrial bioenergetics. Anesthesiology. 1998;88(5):1340-1349.

26. Weinberg GL, Palmer JW, VadeBoncouer TR, Zuechner MB, Edelman G, Hoppel CL. Bupivacaine inhibits acylcarnitine exchange in cardiac mitochondria. Anesthesiology. 2000;92(2):523-528.

27. Iida $\mathrm{H}$, Watanabe $\mathrm{Y}$, Dohi S, Ishiyama T. Direct effects of ropivacaine and bupivacaine on spinal pial vessels in canine. Assessment with closed spinal window technique. Anesthesiology. 1997;87(1): 75-81.

28. Bariskaner H, Tuncer S, Taner A, Dogan N. Effects of bupivacaine and ropivacaine on the isolated human umbilical artery. Int J Obstet Anesth. 2003;12(4):261-265.

29. Rossner KL, Natke E, Liu-Barnett M, Freese KJ. A proposed mechanism of bupivacaine-induced contraction of human umbilical artery smooth muscle cells. Int J Obstet Anesth. 1999;8(1):24-29.

30. Monuszko E, Halevy S, Freese K, Liu-Barnett M, Altura B. Vasoactive actions of local anaesthetics on human isolated umbilical veins and arteries. Br J Pharmacol. 1989;97(2):319-328.
31. Tokinaga Y, Ogawa K, Yu J, Kuriyama T, Minonishi T, Hatano Y. Mechanism of the ropivacaine-induced increase in intracellular $\mathrm{Ca}^{2+}$ concentration in rat aortic smooth muscle. Acta Anaesthesiol Scand. 2007;51(9):1155-1160.

32. Hahnenkamp K, Nollet J, Strumper D, Halene T, Rathman P, Mortier E, et al. Bupivacaine inhibits thromboxane A2-induced vasoconstriction in rat thoracic aorta. Anesth Analg. 2004;99(1):97-102.

33. Newton DJ, McLeod GA, Khan F, Belch JJ. Vasoactive characteristics of bupivacaine and levobupivacaine with and without adjuvant epinephrine in peripheral human skin. Br J Anaesth. 2005;94(5): 662-667.

34. Newton DJ, McLeod GA, Khan F, Belch JJ. Mechanisms influencing the vasoactive effects of lidocaine in human skin. Anesthesia. 2007;62(2):146-150.

35. Weinberg GL, VadeBoncouer T, Ramaraju GA, Garcia-Amaro MF, Cwik MJ. Pretreatment or Resuscitation with a Lipid Infusion Shifts the Dose-Response to Bupivacaine-induced Asystole in Rats. Anesthesiology. 1998;88(4):1071-1075.

36. Litz RJ, Popp M, Stehr SN, Koch T. Successful resuscitation of a patient with ropivacaine-induced asystole after axillary plexus block using lipid infusion. Anesthesia. 2006;61(8):800-801.

37. Rosenblatt MA, Abel M, Fischer GW, Itzkovich CJ, Eisenkraft JB. Successful use of a $20 \%$ lipid emulsion to resuscitate a patient after a presumed bupivacaine-related cardiac arrest. Anesthesiology. 2006; 105(1):217-218.

38. Warren JA, Thoma RB, Georgescu A, Shah SJ. Intravenous lipid infusion in the successful resuscitation of local anesthetic-induced cardiovascular collapse after supraclavicular brachial plexus block. Anesth Analg. 2008;106(5):1578-1580.

39. Litz RJ, Roessel T, Heller AR, Stehr SN. Reversal of central nervous system and cardiac toxicity after local anesthetic intoxication by lipid emulsion injection. Anesth Analg. 2008;106(5):1575-1577.

40. Sirianni AJ, Osterhoudt KC, Calello DP, Muller AA, Waterhouse MR, Goodkin MB, et al. Use of lipid emulsion in the resuscitation of a patient with prolonged cardiovascular collapse after overdose of bupropion and lamotrigine. Ann Emerg Med. 2008;51(4):412-145, 145 e1.

41. Weinberg G. Lipid rescue resuscitation from local anaesthetic cardiac toxicity. Toxicol Rev. 2006;25(3):139-145.

42. Weinberg GL. Lipid infusion therapy: translation to clinical practice. Anesth Analg. 2008;106(5):1340-1342.

43. Weinberg G. Lipid infusion resuscitation for local anesthetic toxicity: proof of clinical efficacy. Anesthesiology. 2006;105(1):7-8.

44. Ludot H, Tharin JY, Belouadah M, Mazoit JX, Malinovsky JM, Successful resuscitation after ropivacaine and lidocaine-induced ventricular arrhythmia following posterior lumbar plexus block in a child. Anesth Analg. 2008;106(5):1572-1574.

45. Mazoit JX, Le Guen R, Beloeil H, Benhamou D. Binding of long-lasting local anesthetics to lipid emulsions. Anesthesiology. 2009;110(2):380-386.

46. Turner-Lawrence DE, Kerns Ii W. Intravenous fat emulsion: a potential novel antidote. J Med Toxicol. 2008;4(2):109-114.

47. Edelman LB, Ripper R, Kelly K, Di Gregorio G, Weinberg GL. Metabolic context affects hemodynamic response to bupivacaine in the isolated rat heart. Chem Biol Interact. 2008 10;172(1):48-53.

48. Brull SJ. Lipid emulsion for the treatment of local anesthetic toxicity: patient safety implications. Anesth Analg. 2008;106(5): 1337-1339.

49. Hiller DB, Gregorio GD, Ripper R, Kelly K, Massad M, Edelman L, et al. Epinephrine impairs lipid resuscitation from bupivacaine overdose: a threshold effect. Anesthesiology. 2009;111(3):498-505.

50. Mayr VD, Mitterschiffthaler L, Neurauter A, Gritsch C, Wenzel V, Muller T, et al. A comparison of the combination of epinephrine and vasopressin with lipid emulsion in a porcine model of asphyxial cardiac arrest after intravenous injection of bupivacaine. Anesth Analg. 2008;106(5):1566-1571.

51. Weinberg G, Ripper R, Feinstein DL, Hoffman W. Lipid emulsion infusion rescues dogs from bupivacaine-induced cardiac toxicity. Reg Anesth Pain Med. 2003;28(3):198-202. 
52. Harvey M, Cave G. Intralipid outperforms sodium bicarbonate in a rabbit model of clomipramine toxicity. Ann Emerg Med. 2007;49(2): $178-185,185$ e1-e4.

53. Harvey MG, Cave GR. Intralipid infusion ameliorates propranololinduced hypotension in rabbits. $J$ Med Toxicol. 2008;4(2):71-76.
54. Weinberg GL, Ripper R, Murphy P, Edelman LB, Hoffman W, Strichartz G, et al. Lipid infusion accelerates removal of bupivacaine and recovery from bupivacaine toxicity in the isolated rat heart. Reg Anesth Pain Med. 2006;31(4):296-303.

\section{Publish your work in this journal}

Local and Regional Anesthesia is an international, peer-reviewed, open access journal publishing on the development, pharmacology, delivery and targeting and clinical use of local and regional anesthetics and analgesics. The journal welcomes submitted papers covering original research, basic science, clinical studies, reviews \& evaluations,

\section{Dovepress}

guidelines, expert opinion and commentary, case reports and extended reports. The manuscript management system is completely online and includes a very quick and fair peer-review system, which is all easy to use. Visit http://www.dovepress.com/testimonials.php to read real quotes from published authors.

Submit your manuscript here: http://www.dovepress.com/local-and-regional-anesthesia-journal 